\title{
ENTREVISTA
}

\section{COM SILVANA NASCIMENTO}

Professora de Antropologia da Universidade de São Paulo, Silvana Nascimento atua na área de antropologia urbana, relações entre campo e cidade, fronteiras urbanas, transexualidades e socialidades. A professora Silvana Nascimento foi entrevistada por Soraya Fleischer, professora de Antropologia da Universidade de Brasília após um envento na Universidade Federal de Viçosa. A entrevista aconteceu em um aeroporto, enquanto aguardavam suas conexões e discutiram as especificidades da antropologia enquanto uma prática compartilhada. A entrevista foi transcrita por Gabriela Crespo, graduanda em Ciências Sociais na UnB.

SORAYA: Hoje é dia 18 de agosto de 2017, são 2:57 da tarde e eu estou aqui no Aeroporto de Confins em Belo Horizonte/MG com a Silvana Nascimento, professora de Antropologia da USP. Nós estamos em trânsito, voltando de um evento muito bacana do qual participamos na Universidade Federal de Viçosa, aqui em Minas Gerais. A gente vai conversar um pouco sobre as diversas facetas do trabalho antropológico e, mais especificamente, da prática de trabalhar coletivamente na academia. Para começar e para a gente poder te conhecer um pouco, Silvana, conta como foi sua formação? E quando você teve a chance de fazer pesquisa de modo coletivo?

SILVANA: Eu fiz graduação em Ciências Sociais na USP e em Jornalismo da PUC/SP. Na verdade, o meu grande sonho era ser jornalista. Então, eu nunca me imaginei como pesquisadora, eu me imaginava uma jornalista com uma formação sólida em Ciências Sociais. Aí eu comecei a trabalhar com Jornalismo, fazer estágio e tudo. Durante a graduação em Jornalismo, eu fazia Ciências Sociais também, mas eu comecei a ter a impressão de que fazer reportagem pontual, ficava superficial. Eu sentia necessidade de fazer pesquisa para pensar sobre as coisas e tal. E aos poucos eu fui me distanciando do Jornalismo e indo mais para pesquisa mesmo. Agora, acho que o que me despertou para a pesquisa coletiva foi um grupo que a gente teve no final da graduação e no começo do mestrado, que era a Revista SextaFeira. A Revista Sexta-Feira era uma revista composta por 8 ou 9 jovens antropólogos graduandos, recém-graduados e mestrandos. (Ela está disponível online com todos os números no endereço <http://www.sexta-feira.com>). A gente queria fazer antropologia fora dos muros, fazer uma antropologia que dialogasse com as Artes, com o Cinema, com o Jornalismo. A gente queria fazer uma coisa um pouco libertária, que não nos aprisionasse nesse modelo acadêmico tradicional, mas a gente também adorava antropologia. 
SORAYA: Essa revista é aquela que tinha um formato horizontal, com muita foto e um papel super bom?

SilvanA: É, isso! E fazíamos o quê? A gente lia todos os artigos que vinham, os nossos que a gente produzia e os textos das pessoas que colaboravam com a gente, que eram professores, pessoas que a gente conhecia. A gente lia todos os textos juntos. Toda quartafeira, a gente lia tudo, comentava tudo junto. E era assim, era um trabalho coletivo super incrível! Até hoje a gente é muito amigo e foi tudo super fundamental, foi super importante à nossa formação. E na Revista, a gente tinha a Florencia Ferrari, que hoje é editora da Editora Ubu (a antiga Editora Jatobá), que tinha um ótimo tino executivo. E ela falou "Vamos montar uma empresa de pesquisa antropológica?". E criamos a Pletora, era o nome dessa empresa. Essa empresa durou até pouco tempo, até uns cinco anos atrás e contava com colegas que não foram para a academia. E durante um bom tempo, a gente oferecia consultoria antropológica. E a gente fazia tudo junto, pesquisa coletiva. Teve uma experiência muito legal na Pletora, que a gente fez uma pesquisa super rica, uma pesquisa de imagem рага o filme "Lisbela e o Prisioneiro". E foi incrível! A gente fez uma pesquisa de imagem, o objetivo era pensar a presença do Nordeste em São Paulo. A gente ia nos lugares lá na Zona Leste, filmava, fotografava e conversava com as pessoas, pegava referências de vestimentas, de cores. O problema é que a gente era muito jovem e não assinou um contrato e não ganhou nem os créditos da pesquisa. Mesmo assim, foi uma experiência super legal de fazer pesquisa fora, a gente fez algumas assim. Pela Pletora também a gente fez uma pesquisa com a Associação Parceria Contra Drogas, que era pra entender o perfil do usuário de maconha, de cocaína em São Paulo. Na equipe, eram três pesquisadores também ligados à nossa empresa. Na época, a gente se reunia numa salinha de um colega, era bem bacana. Então, eu aprendi a fazer desse jeito com os meus colegas de graduação e de mestrado, a gente fazia as coisas juntos, lia junto, pensava junto, comentava os textos juntos, ia para o campo juntos, então a gente já foi fazendo um pouco diferente, entendeu?

SORAYA: Muito bacana! E você lembra quem são esses colegas?

SILVANA: Sei perfeitamente, claro. O Stelio Marras que está hoje no IEB (Instituto de Estudos Brasileiros) na USP; o Renato Sztutman que é meu colega no departamento de Antropologia da USP; a Florencia Ferrari, diretora da editora Ubu; Paula Miraglia, que é diretora do Nexo Jornal; a Paula Pinto e Silva que faz consultoria antropológica para empresas e institutos e atua fora da academia; Evelyn Schuler, que hoje é professora de antropologia da UFSC; a Rose Satiko, que é professora da Antropologia da USP; o Kiko Ferrite que é fotógrafo. Então, 
é esse grupo. Aí depois, já na USP, no Núcleo de Antropologia Urbana (NAU), com orientação do professor José Guilherme Magnani, sempre fazemos pesquisa coletiva. É o estilo dele de fazer pesquisa. E aí eu também fui aprendendo com ele, com o NAU, a fazer pesquisa também dentro da universidade.

SORAYA: Isso já no mestrado?

SILVANA: Isso. Mas eu não fiz muito pesquisa com ele no mestrado, assim, eu aprendia com ele, mas eu não me incluí nas pesquisas que ele estava conduzindo porque a minha área de pesquisa era no Centro-Oeste, em Goiás. Então, eu, participava das pesquisas do Magnani em São Paulo, mas não centralmente, entende? Mas como são feitas as pesquisas no NAU? Esse é um modelo bem próprio do Núcleo de Antropologia Urbana. São expedições. Vamos supor, vamos fazer pesquisa no bairro do Butantã. Quero fazer uma pesquisa para eu entender prostituição no Butantã, por exemplo. Então, a gente tem um modelo de pesquisa já bemsucedida que é assim: Primeiro, a gente faz uma expedição etnográfica, que é de reconhecimento da área com todo mundo. Se tem dez pesquisadores, aí vão os dez pesquisadores caminhando pela rua, conversando com as pessoas, vendo o que tem no bairro, os equipamentos urbanos, as personagens, as coisas que são interessantes, o que vai suscitando daquela caminhada. Então, algumas caminhadas a gente foi fazendo junto, umas duas ou três idas; E depois a gente se divide e faz pesquisa também em duplas ou trios. Então, essa pesquisa sobre o Butantã que eu estou fazendo agora é bem isso. Os meninos nunca estão sozinhos fazendo a pesquisa de campo deles; estão sempre em duplas e trios. Eles fazem relatos de campo, que também são compartilhados por toda a equipe de pesquisa. Isso o Magnani também fez na pesquisa sobre os índios Sateré-Mawé em Manaus e criou o Grupo de Etnologia Urbana. E acabei me inspirando nele. Criamos como se fosse um caderno de campo coletivo, onde os relatos são elaborados e compartilhados entre todos Isso que eu acho muito legal, você poder usar dados de campo dos seus colegas para fazer seu próprio texto, por exemplo. Isso é super comum no NAU.

SORAYA: Em nossas equipes de pesquisadoras na UnB, fazemos isso também. Eu sempre faço uma diferença entre duas versões de um diário de campo. O primeiro diário a gente escreve de modo totalmente livre, um diário de campo à mão ou no computador, com nossos preconceitos, medos, desabafos e tudo o mais. Todas essas coisas que são suas, reservadas e que, por ventura, podem vir a constranger você ou sua interlocutora de alguma forma - esse é o diário completo. E depois você copia tudo isso para outro arquivo e vai tirando o que não quer que seja conhecido, lido ou circulado, esse é o diário editado. E só essa última versão 
você compartilha. Por isso, eu faço a diferença entre o diário completo e o diário editado. E aí a gente faz um tomo cronológico de todos esses diários editados e vira um material que todos podem usar.

SILVANA: Isso, a gente faz isso também.

SORAYA: E quando vamos escrever um artigo, tem todo um cuidado de fazer referência a quem escreveu aquele diário, o cuidado com a autoria.

SILVANA: Sim, isso mesmo. A gente faz isso, a gente tem um arquivo coletivo onde vai colocando os documentos. Nessa pesquisa coletiva com os alunos de graduação, além de pensar a produção de conhecimento de forma coletiva, acho que tem uma coisa importante que é a formação dos alunos, que eles têm uma forma própria de aprender antropologia fazendo dessa forma. Eu acho que é uma forma menos egoísta. Não pensar que a pesquisa é sua, que o interlocutor é seu e que aquela região é sua. A interlocução é com a Regina, por exemplo. A Regina é interlocutora de dez pessoas. E todo mundo compartilha as informações: "Nossa, encontrei com a Regina ontem, ela me contou isso, você não acredita, ela me contou isso". E o outro, "É mesmo?". E a gente vai trocando, então tem essa diferença de pensar a produção de conhecimento realmente coletiva. Você não vai criar uma ideia da sua cabeça, pode até criar, mas eu acho que é menos egoísta.

SORAYA: É menos territorialista também, a relação com os nossos interlocutores é muito menos manipuladora, menos exclusivista.

SILVANA: Sim. E também tem alguns alunos que são mais tímidos e eles aprendem com aqueles que são mais despachados. É aprender junto, tem aquele que é tímido e tem o outro muito tagarela que precisa aprender a ficar quieto, a não perguntar, a deixar rolar. Então, eles vão aprendendo juntos e eu também com eles. Tem sido uma experiência bem bacana. Agora, é outra coisa com os alunos mais velhos, os doutorandos. Eu tenho uma pesquisa pela Fundação de Amparo à Pesquisa do Estado de São Paulo (FAPESP) sobre a relação entre transexualidade e cidade, que inclui cidades da tríplice fronteira amazônica, no Alto Solimões. E há dois doutorandos envolvidos nela, Flávia Melo, que faz pesquisa sobre Bolsa Família e Thiago Oliveira, que faz uma pesquisa sobre relações homoafetivas, ambos nesta região da fronteira. E nesse ano nós três nos encontramos lá e fizemos campo juntos. Eles também conseguiam ver coisas deles, das suas próprias pesquisas e também da minha e eu via as pesquisas deles. Então, a gente conseguiu fazer esse cruzamento. Todos na mesma 
região, mas com finalidades diferentes.

SORAYA: Nas equipes, tem alunos de todos os níveis? E como funciona a formação entre eles?

SILVANA: No bairro do Butantã em São Paulo, eu estou com doutorandos, um mestrando e sete graduandos. Eu vejo que, de um lado, ter muitos orientandos demanda um certo esforço para mim. Mas por ser uma pesquisa coletiva, os estudantes se ajudam mutuamente e me auxiliam também. E nós, como profissionais, também temos que aprender a delegar, aprender a abrir mão. Coordenar a equipe é abrir mão também. Há essa ideia de que a pesquisa é sua, que não quer que ninguém veja, não quer que ninguém compartilhe a sua ideia ou a sua cara, a sua tese. Mas a gente tem que abrir mão. Рara mim, a antropologia é compartilhada e não tem dono.

SORAYA: Quais são os prós e contras da pesquisa coletiva? Quando é que a coisa pode dar errado?

SILVANA: Um aspecto é que você, como coordenadora, tem uma baita responsabilidade. Por exemplo, na Paraíba, a gente fez uma pesquisa com travestis que se prostituem. A equipe era composta por três graduandas e eu. As meninas eram muito jovens e fomos fazer uma pesquisa numa região de muita vulnerabilidade e risco, na beira da estrada, numa região complicada. E eu tinha muito medo por elas. Mas o que aconteceu foi muito interessante, porque uma delas, a Lívia Freire, que hoje é doutoranda em Antropologia pela UFRN, é lutadora de Muay Thai. Então, ela protegia a gente, eu não tinha nenhum medo de estar com a Lívia em campo (risos). Então, tinha uma coisa engraçada de eu poder aprender com elas, com as várias habilidades das jovens pesquisadoras em campo. Isso é muito legal. Eu ficava preocupada com o fato de elas serem muito jovens, de acontecer alguma coisa, ter uma batida policial numa casa de prostituição e elas estarem lá. Mas, ao mesmo tempo, elas eram muito seguras e a segurança delas me deixava segura também. Outro contra é que quando você está numa equipe grande, com muitos jovens, alguns trabalham mais do que outros, e é difícil não tecer comparações. Eu tento evitar muitas competições, mas o ambiente acadêmico, quase que naturalmente, estimula isso desde a graduação.

SORAYA: Quando a gente está sozinha em campo, a gente sabe se virar e se resolve quando encrenca.

SILVANA: Isso. E uma questão que apareceu nessas pesquisas na Paraíba, especialmente, onde 
eu fiquei mais tempo, é que nesse tema da sexualidade, alguns alunos começaram a sair do armário, com todas as implicações que isso envolve, inclusive em relação à transexualidade. A Brune Rapaell Magalhães foi uma delas, que foi minha orientanda de mestrado e hoje é professora em Rondônia. Estudar gênero e sexualidade implica você repensar também sua própria sexualidade. E aí é uma tensão. Repensar sua própria vida, suas questões mais difíceis, íntimas e doloridas.

SORAYA: Mas, ao mesmo tempo, esse sofrimento acaba ficando um pouco mais coletivizado e a equipe de pesquisa também pode funcionar como um grupo de apoio, fazendo tudo isso um pouco menos difícil do que se ela fosse uma pesquisadora solo.

SILVANA: Exato. Teve um menino que era companheiro de uma aluna que, ao participar de um encontro que organizei, junto com Monica Franch (UFPB), ele terminou por se descobrir como homem trans e foi, aos poucos, fazendo sua transição. Foi o primeiro encontro de juventude LGBT da Paraíba, em João Pessoa. O projeto era em conjunto, era meu e da Mônica. Eu estava trabalhando com memória do movimento LGBT, e ela trabalhava com juventude LGBT. E aí um dos meninos que participou se descobriu nesse momento do encontro. Aconteceram vários casos nesse momento. E, depois, tudo isso acabou se tornando inclusive uma pesquisa de TCC.

SORAYA: E autoria, já teve problema com esse aspecto ao longo do trabalho coletivo?

SILVANA: Não tive ainda problema com autoria. Eu publico em co-autoria com meus orientandos, isso é bem comum.

SORAYA: Eu também.

SILVANA: E a gente escreve junto, às vezes eles escrevem mais, às vezes eles me põem no texto e até me surpreendem. Mas nunca tive problema com autoria.

SORAYA: E você acha que esse formato coletivo de trabalho tem repercussões na sua docência, no mundo do financiamento, no mundo dos congressos, por exemplo?

SILVANA: No mundo da docência tem, porque, a partir dessas experiências de pesquisa com os meninos, começando na Paraíba e depois continuando em São Paulo, eu sempre faço pesquisa de campo coletiva em qualquer disciplina que eu dou. Por exemplo, "Antropologia 
1" (que eu dei agora em 2017 e que não necessariamente tem a atividade de pesquisa) ou "Pesquisa de campo em Antropologia". Todo semestre, eu invento algum lugar para a gente fazer uma pesquisa em conjunto, então esse semestre em "Antropologia 1", a gente foi na região onde eu fiz pesquisa para o filme que eu te contei, lá no Largo da Concórdia, que é uma região de migração nordestina e de comércio na Zona Leste. Eu sabia que algumas pessoas nem conheciam aquela região e é legal você apresentar lugares para que as pessoas conheçam São Paulo. Tinha alguns temas, por exemplo: consumo, utilização do espaço público, etc. Em outra vez que eu dei "Antropologia 1", a gente foi para a Rua Augusta, também em São Paulo. Tinham alunos que não conheciam a Augusta, para minha surpresa. Cada grupo escolheu um tema para observar na rua. Era um grupo enorme com 40 alunos e alguns monitores me auxiliaram. Eu não conseguia acompanhar todos eles e dizia, "Olha, daqui a duas horas, eu vou estar no bar tal". Aí eles iam, observavam, se encontravam no bar, conversávamos um pouco sobre o percurso demarcado no território da cidade. Depois escreviam um texto, um relatório, alguma coisa. Então, isso eu tenho feito, todo ano eu faço assim, quem vai fazer minha disciplina já sabe que vai ter campo.

SORAYA: Que bacana isso! Eu dou aula de métodos assim também e até já escrevi sobre essa experiência. Em termos de financiamento, será que a gente tem que pedir dinheiro diferente quando a gente tem equipe? Quer dizer, prever mais passagens, mais diárias? Será que o relatório também é feito coletivamente e os financiadores vão aceitar esse jeito de trabalhar?

SILVANA: O parecer do meu último relatório que enviei à FAPESP justamente elogiou a pesquisa ter sido coletiva. E eu usei muita diária para meus alunos de graduação irem para João Pessoa/PB fazer pesquisa. Todos foram. E foi incrível foi intenso. Você vai fazer pesquisa em São Paulo, você faz duas ou três horas num dia, porque eles têm aula. Outra coisa é você estar intensivamente numa semana inteira, fazendo pesquisa de manhã, tarde, noite. Foi muito bacana quando as meninas foram pela primeira vez. A Verônica Guerra, que foi minha orientanda lá na UFPB, meio que cuidou delas porque ela já sabia qual que era o esquema, já sabia como era porque a gente trabalhava juntas. Na pesquisa coletiva, outra coisa que eu acho que é complicado é como medir a autoridade. Alguns alunos têm tempos diferentes que outros, tem alunos que trabalham pra caramba, trabalham muito, e outros que às vezes trabalham pouco. Tem que ter uma equipe que tenha uma sintonia fina para gente conseguir não ser injusta.

SORAYA: Tem a coisa de a gente ter que ficar interferindo, puxando orelha de aluno. Isso é 
bem chato.

SILVANA: Isso. E tem bolsa, tem prazo.

SORAYA: Em grupo, por contraste, os que trabalham menos percebem e passam a trabalhar mais ou pedem logo para sair.

SILVANA: Por exemplo, é prazo tal, tem que entregar transcrição de entrevista, relatório, diário de campo etc. Tem um grupinho que está entregando no prazo. E a estudante que não faz fica morrendo de vergonha e acaba correndo atrás, pedindo desculpas e entregando. $O$ coletivo ajuda com isso. Na verdade, apesar de ter muita gente, orientar muita gente também facilita. Eu não sofro com orientação, porque flui muito bem. Às vezes, é mais difícil orientar aquele aluno que não se incluiu no grupo, que está lá perdido no mundinho dele, do que orientar os que estão todos juntos.

SORAYA: E pensando que estamos sempre formando profissionais que não necessariamente vão ficar na academia, como essa experiência de pesquisa coletiva define o tipo de profissional que estamos colocando no mercado? Você acha que ele sai diferente da universidade?

SILVANA: Eu tive experiência de trabalhar com um instituto de responsabilidade social durante e depois do doutorado, o Instituto Consulado da Mulher. E acho que a experiência que eu tive com a Revista Sexta-feira e com a empresa Pletora me deu um super jogo de cintura para trabalhar em diferentes ambientes. Eu trabalhava em um instituto dentro de uma multinacional. Com toda a minha leitura antropológica, eu conseguia falar a linguagem de várias pessoas. Como a gente não pensa só de uma perspectiva, você fica com um jogo de cintura. Nesse sentido, acho que a antropologia é muito plural.

SORAYA: Então, você sai mais polivalente!

SILVANA: Exatamente, polivalente, essa palavra é perfeita. É exatamente o que eu acho. Você consegue fazer várias coisas, pode trabalhar com cinema, com produção de cinema, com pesquisa para empresas, com organizações não-governamentais, associações, movimentos sociais...

SORAYA: Há uma polivalência em termos de tarefas e áreas de trabalho. Mas também, pelo 
fato de ter convivido em equipe, com seis ou sete colegas pesquisadores, você também já conviveu com um tímido, outro que fala muito, outro que monopoliza a fala, um que é super emocional, outro que sofre com tudo. Você acaba tendo que conviver com vários tipos humanos, tendo que aprender a ter paciência com os seus colegas, com os ritmos, as crises e tal. O trabalho coletivo nos ajuda a desenvolver uma capacidade de lidar com um repertório maior de tipos humanos. Quando a gente está naquela carreira individual (e a academia nos formata muito mais para esse perfil), você pira quando você encontra um colega muito diferente, você fica muito incomodado com a idiossincrasia alheia.

SILVANA: Esse perfil mais individual acaba não sabendo se relacionar com as pessoas. Mas, sabe, eu dou uma pressionada para fazer pesquisa acadêmica depois. Eu tenho muitos alunos que são muito bons, você identifica que aquela pessoa poderia fazer uma pesquisa incrível de mestrado, tem perfil, mas talvez não esteja preparado para a minha pressão ou para a pressão do mundo acadêmico. E tenho que saber lidar com isso e deixar a pessoa seguir seu próprio caminho profissional.

SORAYA: Você é muito presente.

SILVANA: Isso, eu sou muito presente, às vezes demais. Então às vezes eu preciso segurar minha onda, porque às vezes a pessoa tem perfil para outra coisa também, não necessariamente para a academia. Eu tenho que deixar ir.

SORAYA: Sim, para ele descobrir o estilo dele.

\section{SILVANA: Exatamente.}

SORAYA: Você acha que tem etapas mais fáceis e outras mais difíceis para fazer pesquisa coletiva?

SILVANA: A parte do campo eu acho a mais fácil, escrever junto é difícil, a análise e a interpretação também são difíceis. Como posso articular meu projeto maior e as minhas questões a longo prazo e as questões dos alunos que são mais pontuais ou que são outras questões? Por exemplo, estamos fazendo pesquisa e, de repente, a gente acha um terreiro. $\mathrm{E}$ uma aluna da equipe se descobre naquele terreiro e vai por outro caminho. Como é que eu vou articular as minhas questões teóricas, a minha pesquisa, que eu tenho que fazer um relatório e prestar contas com esse novo tema e espaço que ela está frequentando? 
SORAYA: Pode ser que você seja a autora protagonista em um tema e uma autora ou pesquisadora mais periférica no outro tema, campo, texto.

SILVANA: Isso. E outra coisa importante da pesquisa coletiva que eu tenho feito com os alunos é sempre incluir um braço de atividades de extensão. Junto com o projeto de pesquisa, eu sempre cadastro um projeto de extensão também, para sempre pensar algum desdobramento. Isso atrai muito os alunos, às vezes até mais do que a pesquisa. No caso da pesquisa com as prostitutas, a gente foi conhecer o posto de saúde, conversar com as pessoas ali. A gente foi no Centro de Referência de DST/AIDS, na associação de moradores da favela São Remo, lá do lado da USP. Fomos conhecer a Polícia Federal que tem a sua sede próxima ao campus. Para pensar, para sair um pouco do lugar só da pesquisa. Nessa pesquisa no Butantã, em 2016, conseguimos trazer para dentro da universidade um debate sobre o bairro onde está localizada a Cidade Universitária, com a participação de ativistas locais, artistas, educadores e também servidores da própria USP. Foi uma iniciativa bastante interessante e mostrou o quanto a USP está distante da realidade do seu entorno. Na Paraíba, desde o início, trabalhamos em parceria com o movimento LGBT e com ativistas travestis. Por exemplo, organizamos uma exposição "Variações do Feminino" - com fotografias de travestis, mulheres transexuais e transformistas paraibanas - que circulou em diferentes cidades paraibanas com o intuito de quebrar preconceitos e estereótipos e mostrar diferentes facetas dessas pessoas. Também organizamos, como já falei, o primeiro Encontro da Juventude LGBT da Paraíba, em parceria com os movimentos sociais de João Pessoa e também do interior, como Campina Grande e Catolé do Rocha. Poderia passar horas contando essas histórias para você!

SORAYA: Você falou da Mônica Franch, do Magnani, do seu trabalho. Eu também tenho feito muita coisa de modo coletivo na UnB. Acho que poderíamos organizar um evento, um seminário para reunirmos e debatermos experiências coletivas desse tipo.

SILVANA: Sim! Seria muito massa.

SORAYA: Bom, minha querida, é isso. Estou vendo que a fila do seu embarque está terminando e você precisa pegar esse voo para voltar para casa. Agradeço muito pela ótima companhia durante os últimos dias e por esse produtivo bate-papo aqui no aeroporto de Confins. Foi um prazer te ouvir e aprender contigo! 